\title{
Correction to: Novel Design for Reversible Arithmetic Logic Unit
}

\author{
Rigui Zhou' ${ }^{1}$ Yancheng $\mathrm{Li}^{1} \cdot$ Manqun Zhang ${ }^{1}$. \\ BenQiong $\mathrm{Hu}^{2}$
}

Published online: 18 October 2017

(C) Springer Science+Business Media, LLC 2017

\section{Correction to: Int J Theor Phys (2015) 54:630-644 \\ https://doi.org/10.1007/s10773-014-2255-x}

The original version of this article unfortunately contained a mistake. Authors' names in reference 9 was incorrectly presented. The corrected reference is shown below.

9. Thomsen M.K., Glück R., Axelsen H.B.: Reversible arithmetic logic unit for quantum arithmetic. J. Phys. A Math. Theor. 43(38), 2010 (2002)

The online version of the original article can be found at https://doi.org/10.1007/s10773-014-2255-x.

Yancheng Li

lychen12@yeah.net

Manqun Zhang

zhangmanqunn@126.com

1 College of Information Engineering, East China JiaoTong University, 330013 Nanchang, Jiangxi, People's Republic of China

2 College of Management Science, Chengdu University of Technology, Chengdu 610059, China 